\title{
Recent Advances on the Oil-Free Scroll Compressor
}

\author{
Peng Bin ${ }^{1,2, *}$, Arnaud Legros ${ }^{3}$, Vincent Lemort ${ }^{3}$, Xie Xiaozheng ${ }^{1,2}$ and Gong Haifeng ${ }^{4}$
}

${ }^{I}$ School of Mechanical and Electronical Engineering, Lanzhou University of Technology. Lanzhou 730050, P.R. China; ${ }^{2}$ Wenzhou Pump \& Valve Engin. Research Institute, Lanzhou University of Technology. Wenzhou 325105, P.R. China; ${ }^{3}$ University of Liege, Energy Systems Research Unit, Liege, 4000, Belgium; ${ }^{4}$ College of Mechanical Engineering, Chongqing University of Technology, Chongqing, 400054, P.R. China

Received: April 7, 2015; Accepted: October 12, 2015; Revised: November 9, 2015

\begin{abstract}
Traditionally, scroll compressors are mainly made of metallic parts and oil is used to lubricate the friction surfaces and reduce discharge temperature and leakage. But for the food processing, medical systems, textile manufacturing, fuel cell system, and other super-clean fields, the oil-less operation is critical. The oil is strictly forbidden in the working chambers of the scroll compressor in order to get the oil-free compressed air. So it is very important to develop the oil-free scroll compressor (OFSC). In this paper, the working principle and structure characteristics of the OFSC are investigated. Some of research works and the recent patents in this area are described and analyzed in detail, especially the water injection and air cooling OFSC. The future development on an OFSC is also presented. The analysis results demonstrated that there is dramatic growth potential in OFSC field.
\end{abstract}

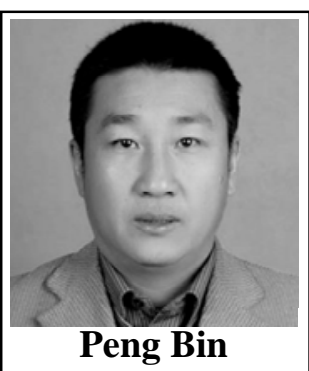

Keywords: Cooling, oil-free, performance, scroll compressor, sealing, structure, water.

\section{INTRODUCTION}

Scroll compressor is a new kind of positive machine. Scroll compressor has many favorable features, including simple structure, lower vibrations, and high volumetric efficiency relative to other types of compressors. With the development of the scroll compressor, it has been become more and more popular in many fields.

In order to achieve superior operating efficiency and reliability, oil is injected into the compression chambers of scroll compressors. The motivation for oil injection in scroll compressors is that oil should be able to seal the leakage gaps between fixed and orbiting scrolls. In addition, the oil can help to control the discharge temperature of the compressor by absorbing some of the heat of the fluid as it goes through the compression. However, for the food processing, medical systems, textile manufacturing, cryogenics, fuel cell stacks and other ultra-clean applications, oil stains cannot be tolerated and is strictly prohibited in this kind of field. One possible means of achieving oil-free compressed air is through the use of oil filter, and the other one is to adopt an OFSC. Using the OFSC is more valid compared with oil filter because it eliminates the need for lubricants.

OFSC means no oil in working chambers. It can provide oil-free and contaminant-free compressed air, eliminate environmental emissions and protect natural resources. This paper will describe some of the recent advances in the area of

\footnotetext{
*Address correspondence to this author at the School of Mechanical and Electronical Engineering, Lanzhou University of Technology. Lanzhou 730050, P.R. China; Tel: 086-931-2973860; Fax: 086-931-2757293; E-mail: pengb2000@163.com
}

OFSC. In part 2, a basic background of scroll compressor will be presented. In part 3 , the recent technologies of OFSC will be given and discussed. In part 4, a typical OFSC will be presented. In part 5, the paper will be concluded with some perspectives of future research [1].

\section{SCROLL COMPRESSOR}

Figure 1 is the typical horizontal scroll compressor where the main parts are presented. In the scroll compressor one scroll is fixed, the other orbiting scroll is connected to the driven crankshaft. The phase difference of fixed and orbiting scrolls is $180^{\circ}$. The anti-rotational mechanism is located between the shell and the orbiting scroll. The goal of the antirotational mechanism is simply to avoid the rotation of the orbiting scroll and maintain the relative angle of the fixed and orbiting scrolls, still allowing its orbiting movement. The working chambers between the fixed and orbiting scrolls moved along the profiles. The working principle of OFSC is shown in Fig. (2). Fluid gets trapped in the suction chamber (a) through a port. With the crankshaft rotates, the suction chamber moved through the profiles which has now become the compression chambers (b), (c) and (d). In the compression process, the compression chambers is decreasing gradually and compressing the fluid. When the compression chamber is connected to the exhaust hole in the center discharge region (e) of the fixed scroll, the fluid is discharged by the outlet. In scroll compressors, the fixed and orbiting scrolls define two paths for the working fluid. Usually, the two paths are symmetric, leading to the same pressure changes inside each one [1]. 


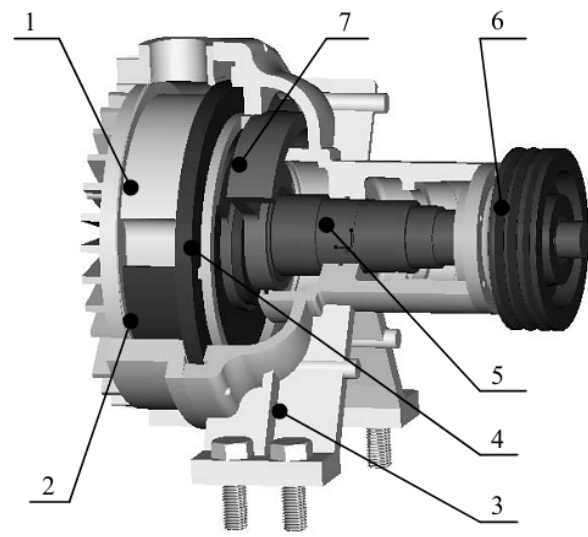

1. Fixed scroll 2. Orbiting scroll 3. Shell 4. Anti-rotational mechanism 5. Crankshaft 6. Belt with small counterbalance 7. Big counterbalance

Fig. (1). The typical horizontal scroll compressor.

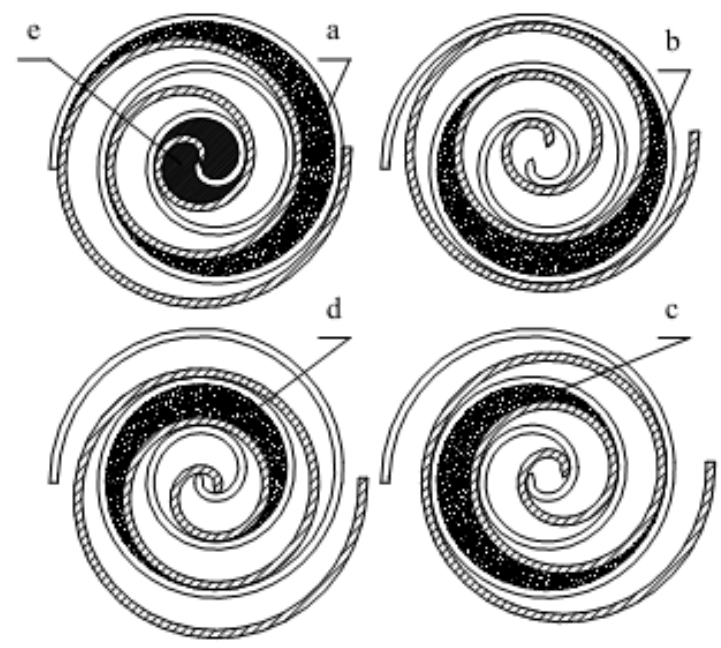

Fig. (2). Working principle of scroll compressor.

In 1886, the working principle of a scroll compressor first appeared in the Italian patent literature (Beseler, 1887) [2]. In 1905, the French engineer formally proposed the principle and structure of a scroll compressor, and applied for a US patent (Leon Creux, 1905). In the 1970s, the US
company-ADL firstly solved the scroll ends wear compensation sealing technology which guided the technological growth and put scroll machines into practice. In 1981, scroll compressors began to be mass-produced in Japan by Sanden Corp. It was the first company to begin the production for automotive air conditioning scroll compressors. In 1983, Hitachi began to use 2-5HP scroll compressors for refrigeration and air conditioning. In 1987, Copeland Corp. has turned scroll compressor theory into practical reality with mass production. At present, with the widespread use in the industry areas, scroll compressor has become the main product in small and medium sized compressors [3].

Almost 4700 US and European patents have been disclosed in scroll compressor area during the year 1975-2015. Figure 3 is US patents and European patents growing trend of scroll compressor (1975-2015). The main development period began in 1982 and the patents of scroll compressor grew to the peak in 2002. There is a small fall after 2002 and then gradually increased till it reached the maximum in 2014. Figure 4 presents the major scroll compressor companies that have patented innovations about scroll compressors between 1975 and 2015. From the scroll compressor patents and market share analysis it shows that Copeland Corp. is the biggest competitor in scroll compressor area. The companies from US and Japan account for nearly two-thirds of total patents. Today, OFSC due to its unique features and energy saving, has aroused many researchers' great interest. Along with the widely used of OFSC in requirement of clear environment of industry, OFSC is becoming the development trend in this field [4].

\section{OFSC}

In academic publications, some researchers have done a lot of works in OFSC. Lai [5] designed and tested an OFSC for an electric vehicle. This paper focused on the topics of concept design and analysis, component manufacturing, prototyping assembly and performance testing. In structure design, the influences of scroll pitch, wrap height, wrap width and crank radius for compressor performance were considered. Figure 5 is the prototype of OFSC. An optimized combination of geometric scroll parameters, accurate counterweight calculations, suitable bearings and precise machining were used to develop this OFSC. Figure $\mathbf{6}$ is the comparisons of the performance test results with different design changes of axial and radial clearance. In Fig. (6), the [Change1] re-

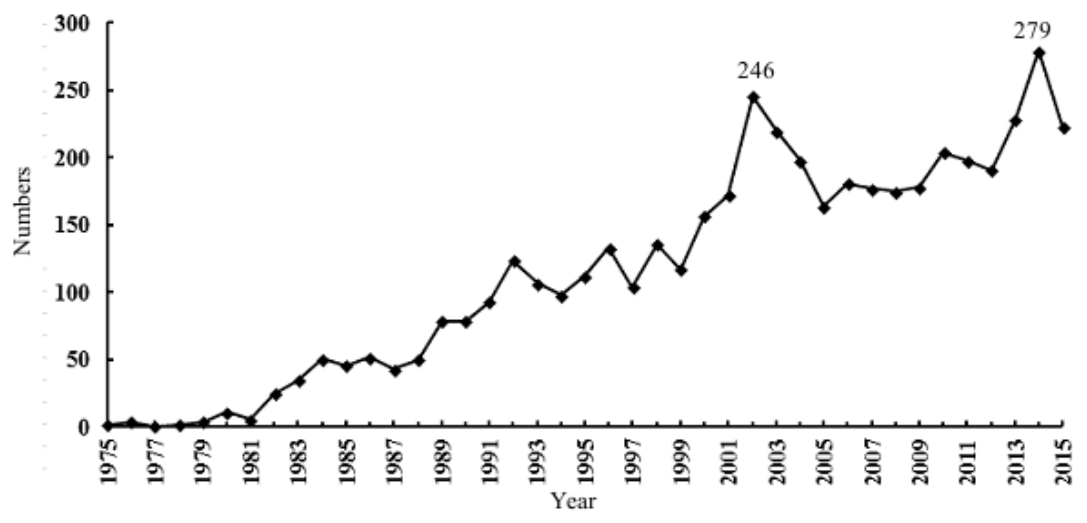

Fig. (3). US patents and EP patents growing trend of scroll compressor (1975-2015). 


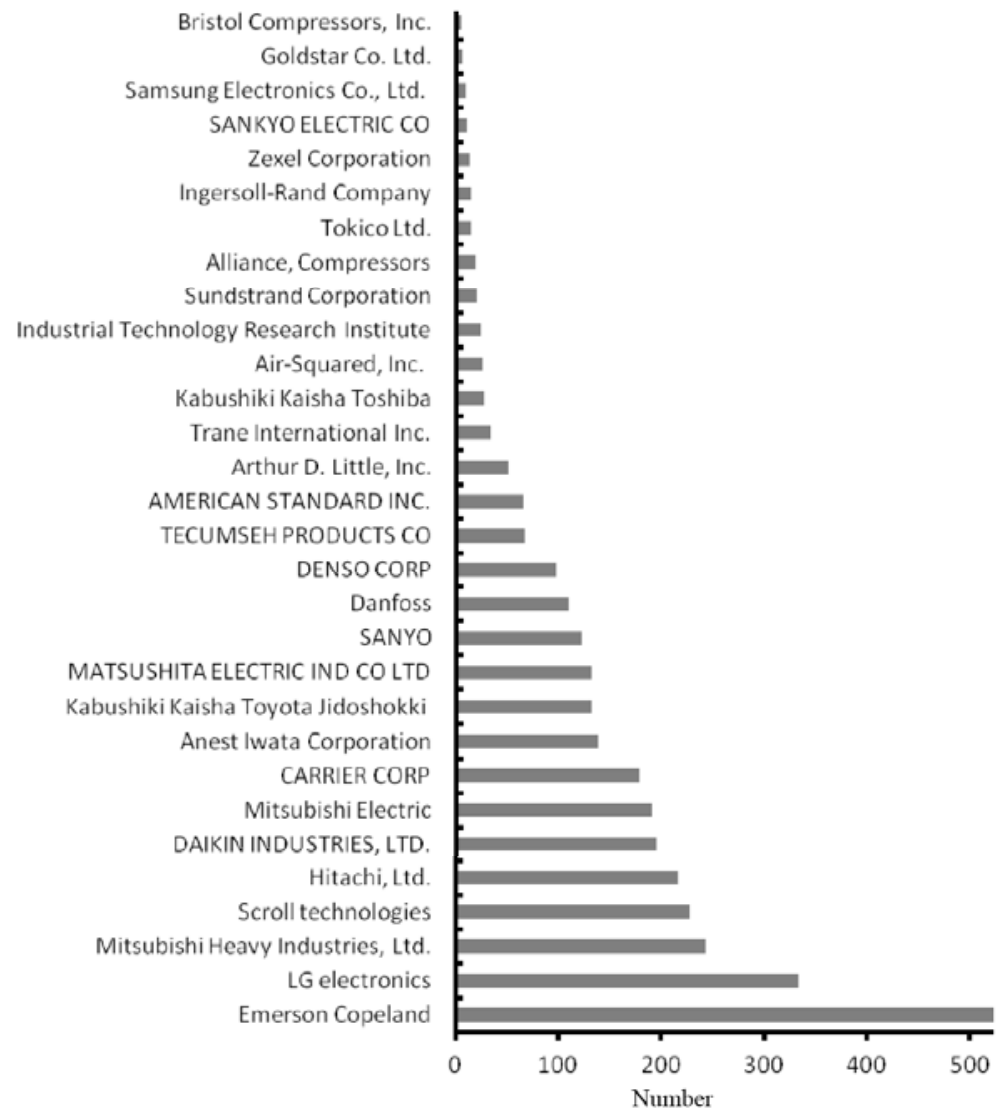

Fig. (4). Major scroll compressor companies from US patents and EP patents analysis (1975-2015).

duced the size of axial and radial clearance about $50 \%$ and $30 \%$ respectively from the original design. The [Change 2] further modified the axial clearance about $10 \%$ smaller than [Change 1]. The test results showed that the performance of newly developed prototype compressor satisfies the original requirements. Large clearance will lead to large leakage and the lower limit of the clearance is related to what is feasible in practice (tolerances, machining imprecision and deformation). So the appropriate size of axial and radial clearance is very important for OFSC performance.

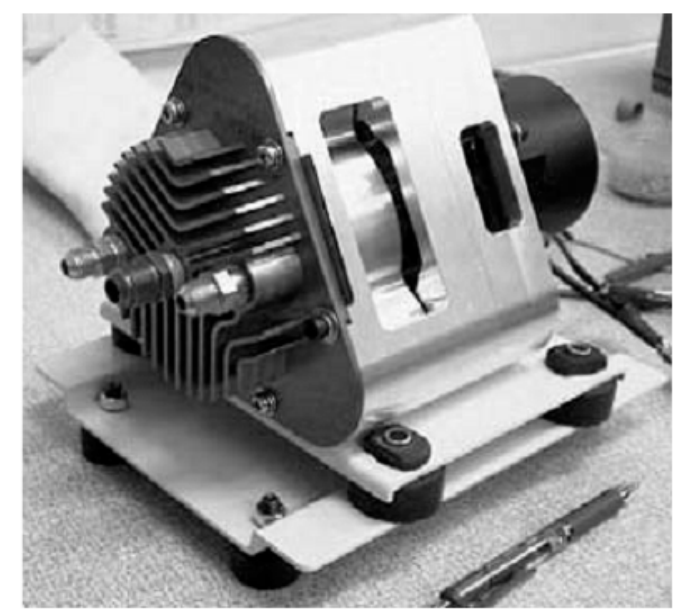

Fig. (5). The prototype of OFSC.

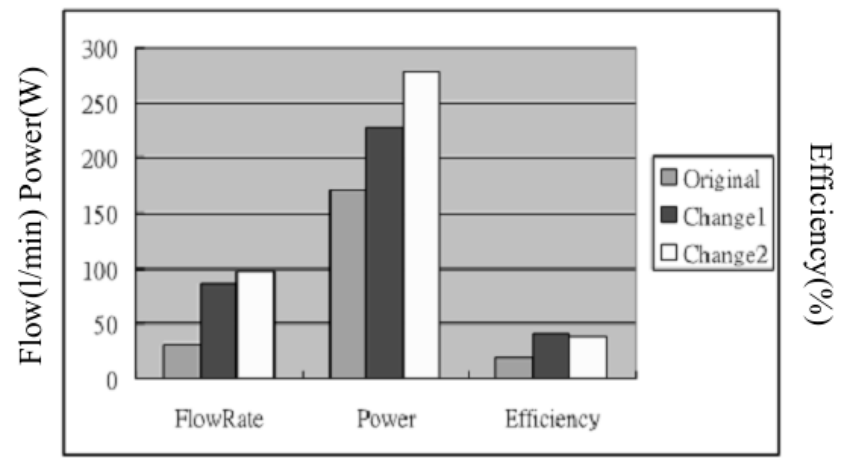

Fig. (6). The performance of OFSC.

Zhao $[6,7]$ investigated the detail performances of the water injection OFSC for a fuel cell. Figure 7 shows the structure of scroll compressor without using oil and grease. In order to lower the discharge temperature, water is used to control the discharge temperature of the compressor and lubricate the friction surfaces. In order to reduce the the overall machine weight and avoid rusting, aluminum alloy and titanium alloy are used as the materials of the fixed and orbiting scrolls. Teflon is used in the bearing to reduce friction and wear. A mathematical model of OFSC for the automotive fuel cell was investigated. The heat transfer and leakage in scroll compressor were considered. The numerical simulation results of compressor power are in good agreement with the test results in less than $7.28 \%$ of the mean deviation as shown in Fig. (8). 


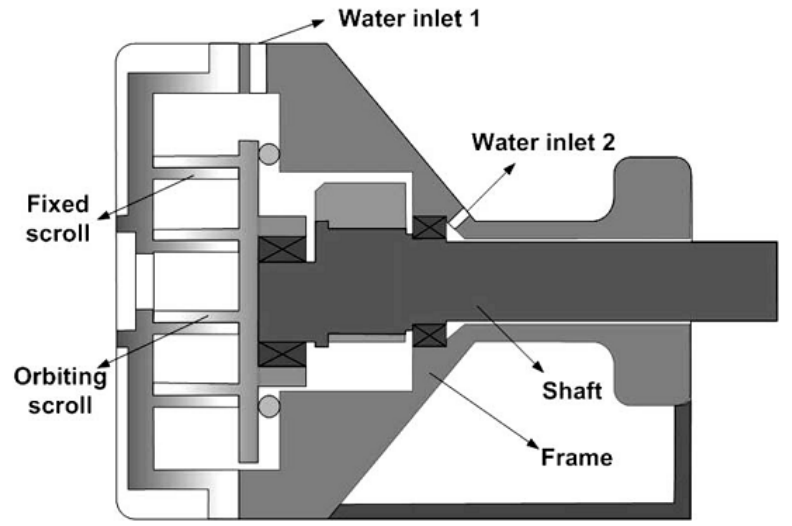

Fig. (7). The structure of water injection scroll compressor.

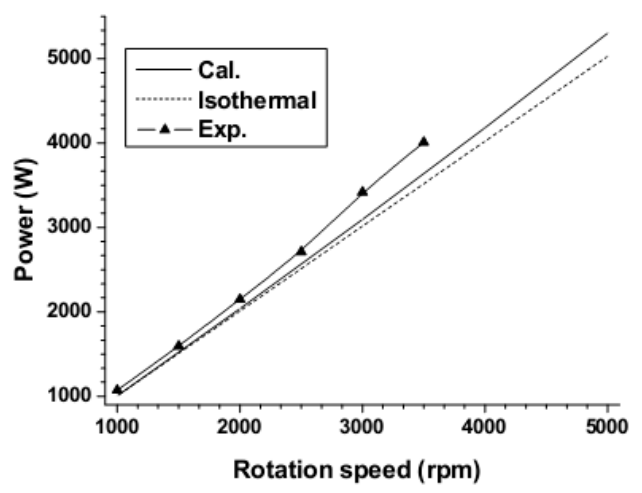

Fig. (8). Comparison of compressor powers.

Wang [8] constructed an OFSC as shown in Fig. (9) and investigated the performance of compressor used in the refrigeration system of the aerospace and aircraft. The selflubricating, long-life tip seal ensures the axial gap of compressor. The ball bearing is adopted as anti-rotational mechanism to maintain the relative angle and movement of scrolls. The compressor can operate efficiently without oil and expensive filtration. The gap of the orbiting and fixed scrolls is kept around $30 \mu \mathrm{m}$. The mathematical modeling of the OFSC was developed. The numerical simulation results show good agreement with the test results with less than mean deviation of $10 \%$.

Yanagisawa et al. showed that the volumetric and total efficiencies of the compressor are $87 \%$ and $56 \%$ respectively under the conditions of discharge pressure $700 \mathrm{kPa}$ and rota-

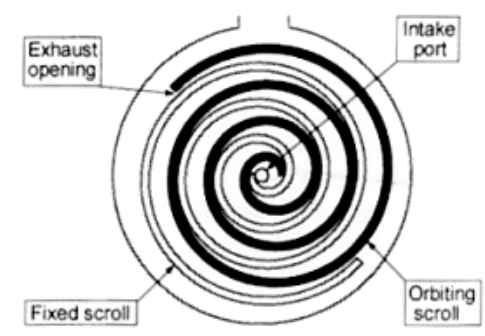

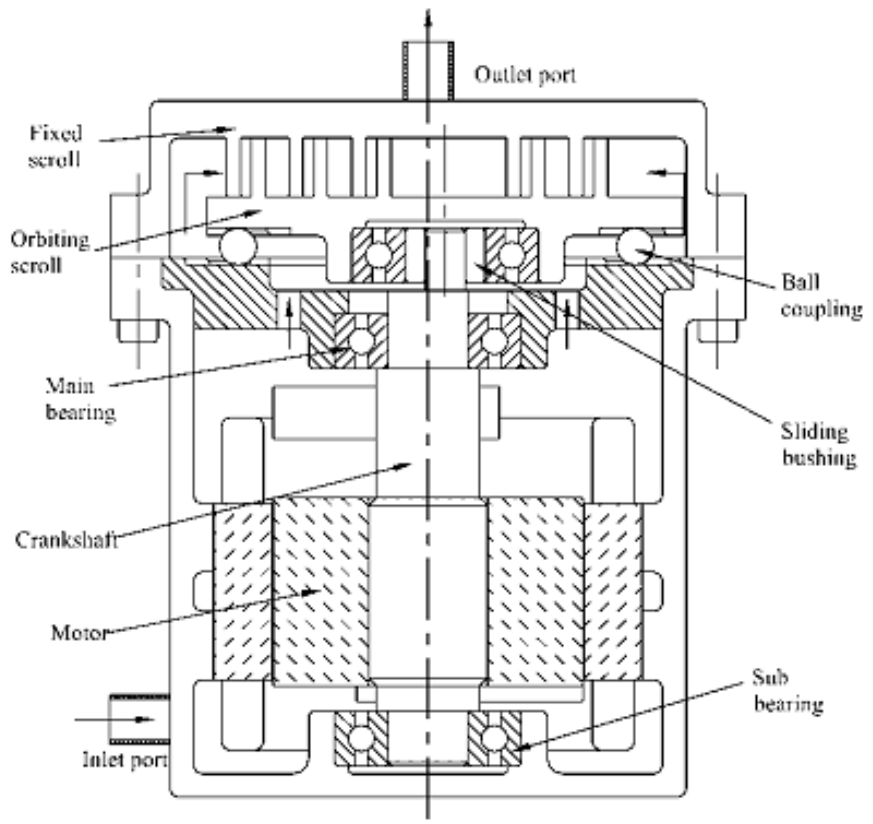

Fig. (9). The OFSC used in the refrigeration system.

tion speed 2720rpm. Figure $\mathbf{1 0}$ is the structure of OFSC. On the other hand, Yanagisawa showed the performance of the same compressor, but in air expansion mode, to be respectively $76 \%$ and $60 \%$ for volumetric and total efficiencies, which occur under the conditions of having a pressure supply of $650 \mathrm{kPa}$ and a rotation speed of $2500 \mathrm{rpm}[9,10]$.

Aoun et al. and Lemort et al. [11, 12] investigated experimentally the performance of a scroll expander that comes from an OFSC, which was tested by Yanagisawa. Aoun improved the volumetric efficiency by replacing the original tip seal of the expander by a polytetrafluorethylene (PTFE) seal. Experimental results obtained after the modification show $20 \%$ increase in the volumetric efficiency without affecting the isentropic efficiency. The increase in volumetric efficiency is mainly due to the lower axial clearance between the seals and the wraps of the expander, while the isentropic efficiency was maintained due to the low leakage flow. Lemort used water steam and HCFC-123 as working fluid to investigate the performances of a scroll expander. Two different mathematical models of the expander are developed. Through performance test, the models are finally verified. The analysis results provide guidance for the structure design of scroll expander.

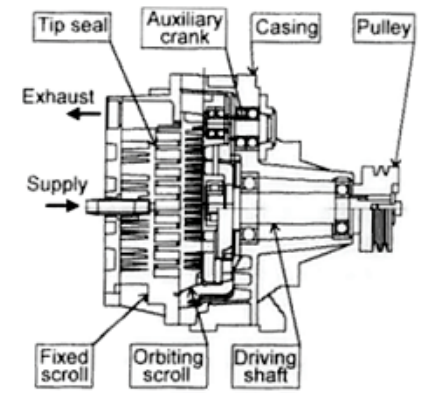

Fig. (10). The structure of OFSC. 


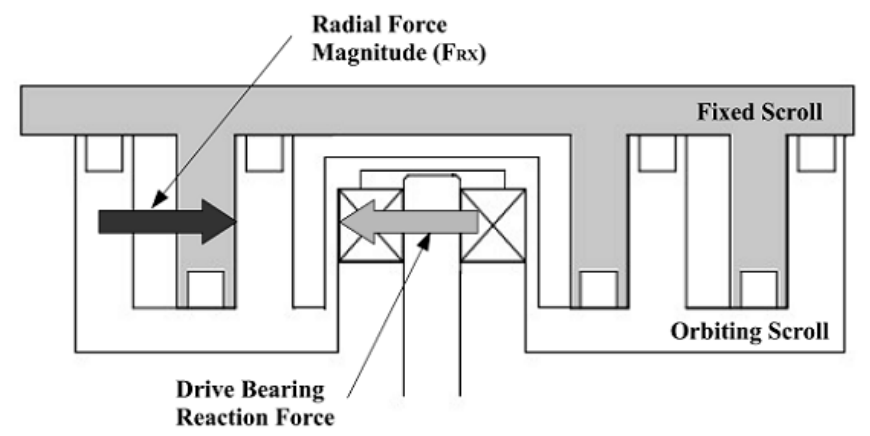

Fig. (11). Plastic OFSC.

Shaffer [13] designed a new compressor and built from both plastic and metallic materials. The proposed compressor design mitigates the overturning moment by placing the crank shaft bearing in-line with the resulting radial force as shown in Fig. (11). It can eliminate the overturning moment. It is important to include a self-lubricating material between surfaces in contact. Plastic compressors are significantly more susceptible to thermal deformation than metallic compressors. Because of this, the plastic compressor with an orbiting scroll built from PEEK shows a reduction in performance from the fully aluminum compressor. Plastic compressors require lower precision and cost compared with traditional metallic compressors.

There are many recent patents on OFSC. Shigeru [14] presented an OFSC with embedded shaft as shown in Fig. (12). The driving bearing is embedded into $1 / 2$ the height of the orbiting scroll. Seiichi [15] also presented a scroll machine with first and second bearings as shown in Fig. (13). A driving shaft penetrates the orbiting scroll and the fixed scroll base. The two designed structures change the center of gravity and the point of action of force generated by the compressed gas, and eliminated the moment load of orbiting scroll. So, it ensures the stable motion of orbiting scroll and can operate with high degree of reliability despite that no lubrication is conducted for the parts in the compression chambers.

Shuji $[16,17]$ provided an OFSC as shown in Fig. (14) that can obtain high compression efficiency with highly accurate sealability. The invention particularly has such a constitution that a seal fitted in each of the wrap end surfaces of scrolls is integrated with a backup seal. A surrounded space between the slide surface and the wrap is sealed with the chip seal. The scroll compressor having an orbiting scroll and a pair of fixed scroll can balance the axial force very well.

In order to obtain vacuum pressures below 1 torr, Grenci [18] presented a simplified sealing method to produce an oilfree scroll type vacuum pump as shown in Fig. (15). One dynamic orbiting vacuum seal between the two scrolls is used to prevent atmospheric gas from entering.

Akira and Zhenmin $[19,20]$ presented an orbiting scroll with cooling holes of an OFSC as shown in Figs. (16 \& 17). The cooling medium passed through the cooling holes to directly cool the orbiting scroll.

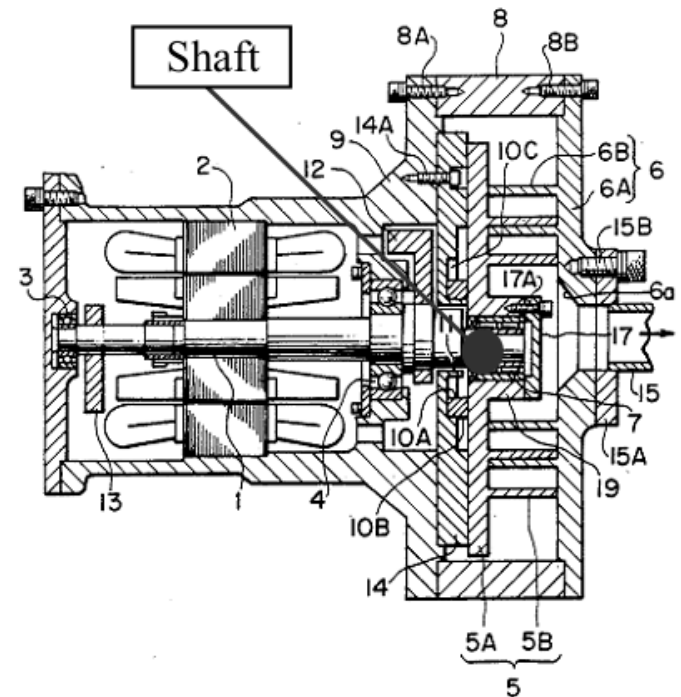

Fig. (12). An OFSC with embedded shaft.

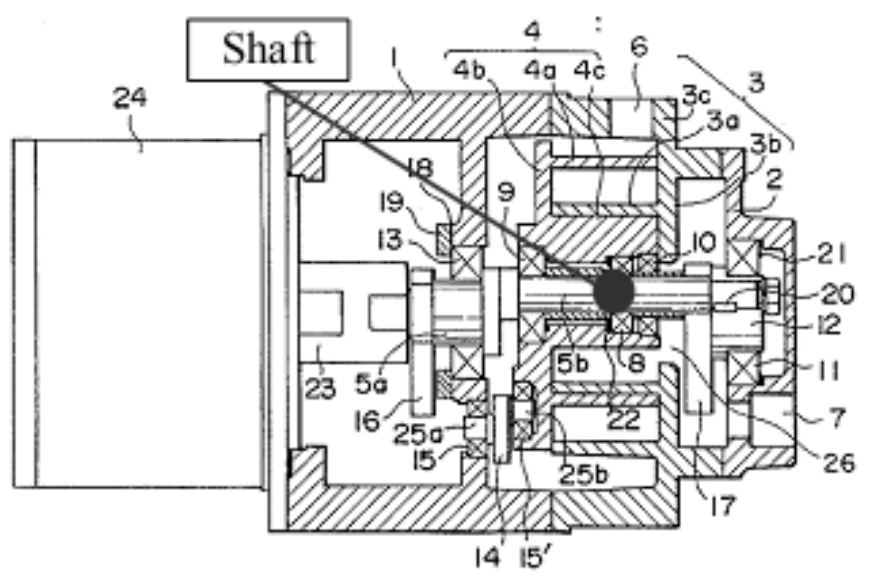

Fig. (13). Scroll machine with first and second bearings.
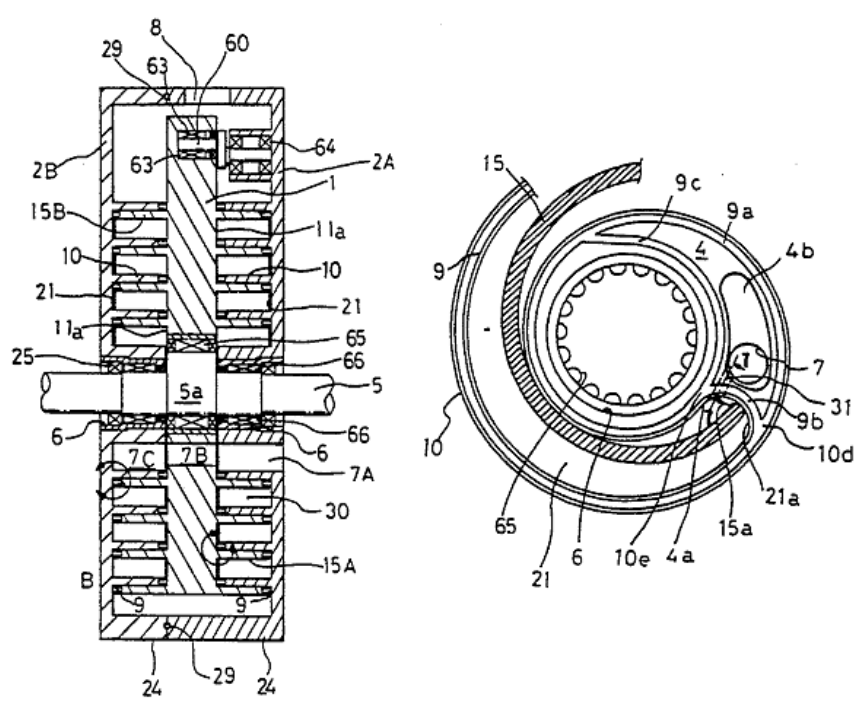

Fig. (14). Scroll-type fluid machinery with seals for the discharge port and wraps. 


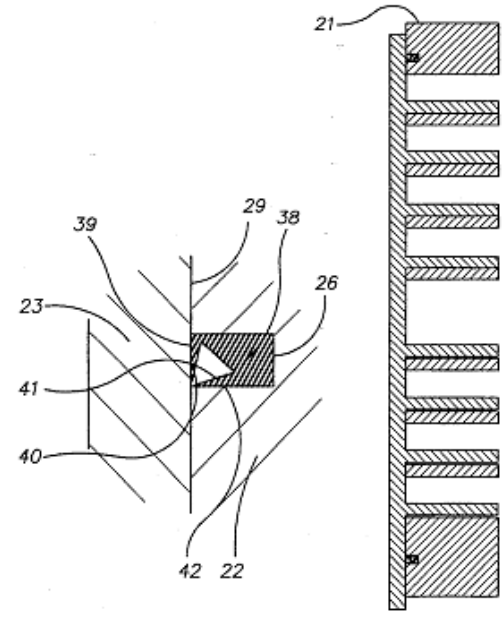

Fig. (15). Oil-free vacuum pump.

Akira [21] presented an OFSC as shown in Fig. (18). The scroll compressing mechanism blocks are driven by a dualshaft motor (34) through belts ( 35 and 36). The two fans (39 and 41) are used to cool the scroll compressing mechanism blocks (23 and 24). The compressed air is cooled by an aftercooler and supplied to the compressed air user side.

Masaru, HShuji, Guangyu and Guangyan [22-26] presented the structure of oil-free scroll fluid machinery respectively as shown in Figs. $(\mathbf{1 9} \& \mathbf{2 0})$. The main characteristics of the scroll machines are that a driving shaft penetrates the orbiting scroll to improve its stability and two fans are used to cool the oil-free scroll fluid machinery.

Kazuaki [27] presented a kind of cooler as shown in Fig. (21). In the OFSC, a cooling fan (4) is installed on the one of shaft of a double-axis motor, and a belt is installed on the other shaft. A main duct is formed on the suction side of the cooling fan and is interconnected in series with a cooling air outlet of the compressor element.

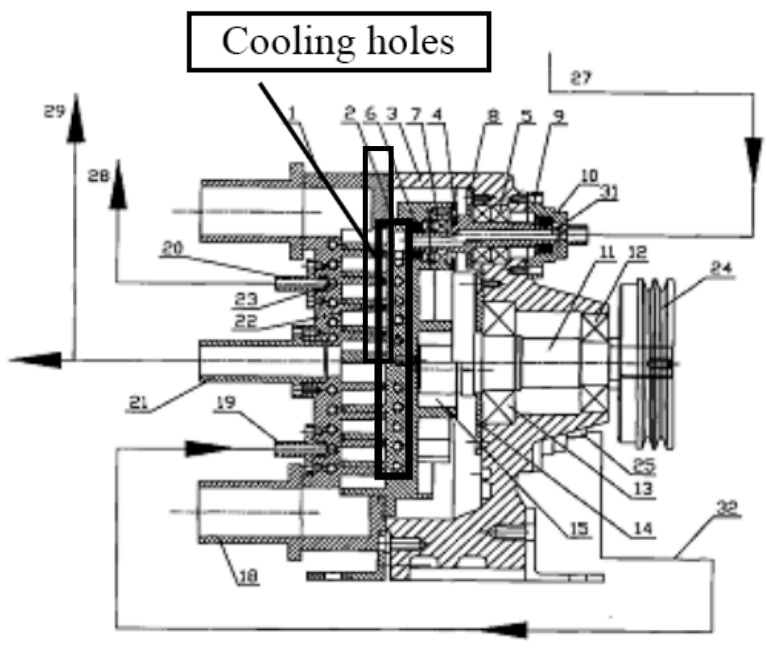

Fig. (17). Constant low temperature OFSC.

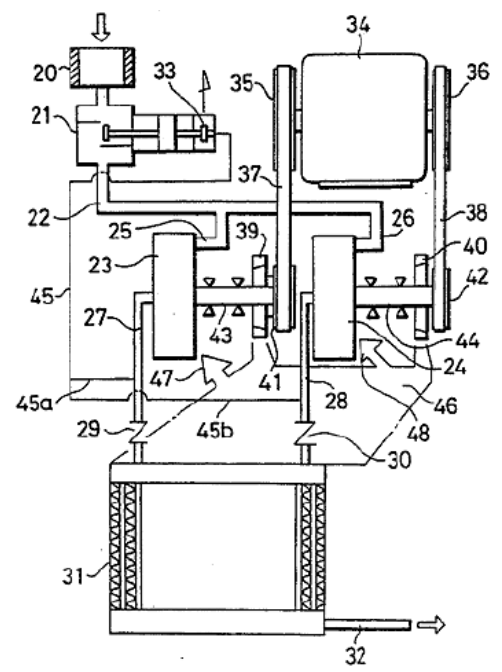

Fig. (18). The dual-shaft OFSC.

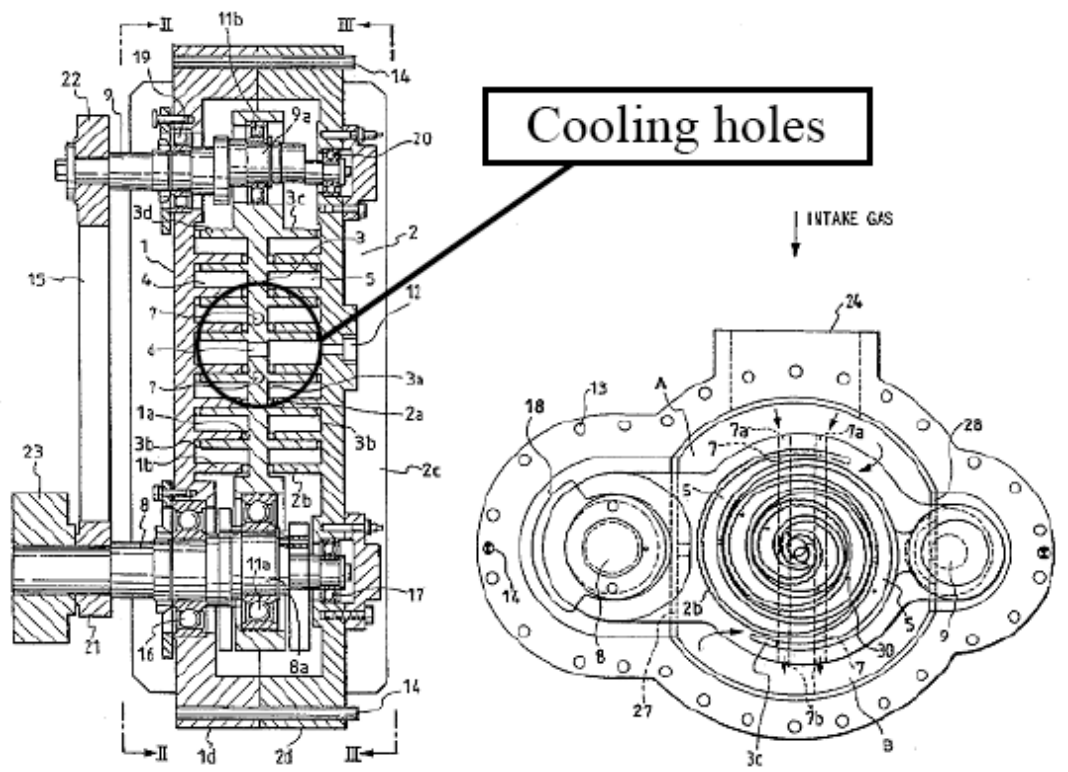

Fig. (16). Scroll compressor with cooling holes in orbiting scroll. 


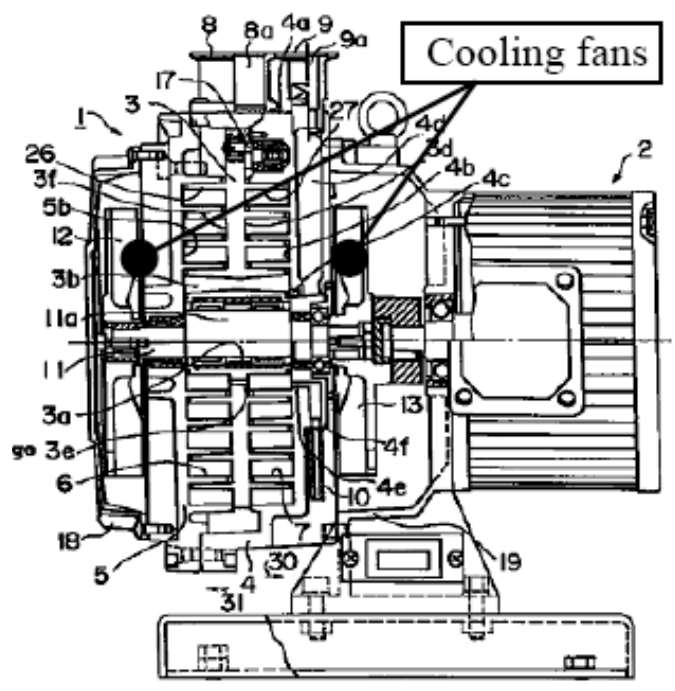

Fig. (19). Oil-free scroll vacuum pump.

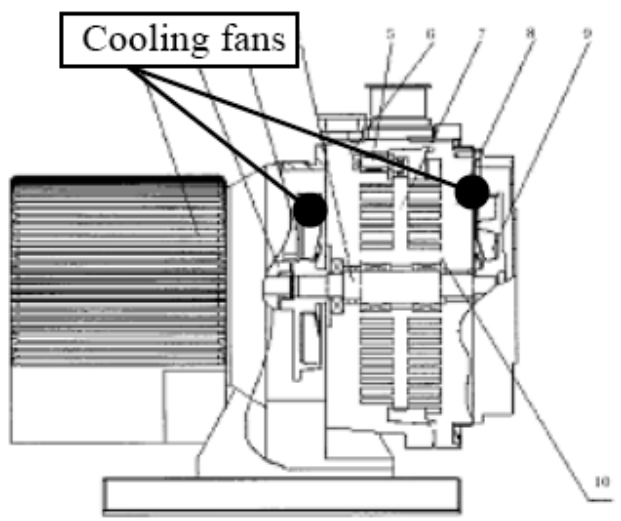

Fig. (20). Oil-free scroll fluid machine.

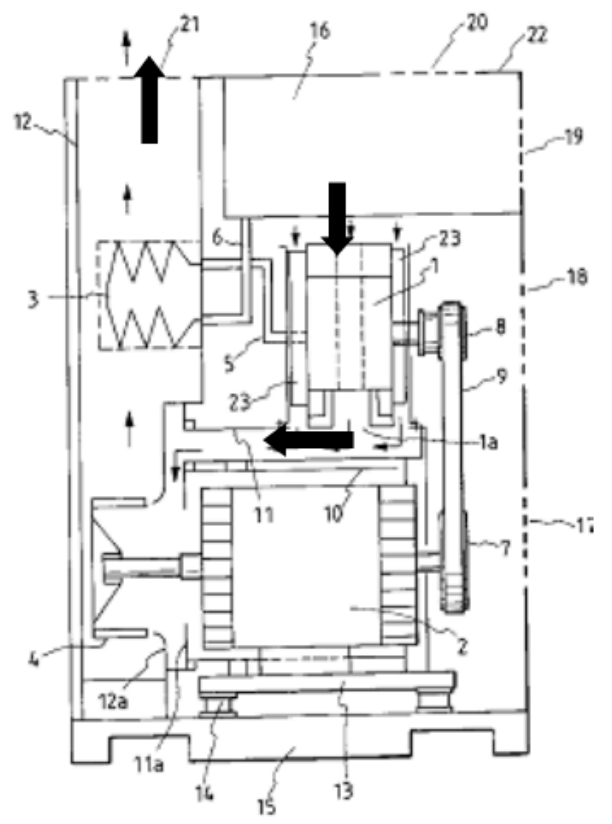

Fig. (21). A cooler in an OFSC.
Kazutaka and Atsushi [28, 29] presented a method to cool oil-free scroll fluid machine as shown in Figs. (22 \& 23). Cooling air is sucked into an inner peripheral side of a centrifugal fan (Figs. (23-31)). Cooling air guiding through a fixed cooling passage provided at the oil-free scroll fluid machine is allowed to flow out of a fixed outlet and an orbiting outlet, respectively. Different rotation direction of centrifugal fan will produce different flow direction of cooling air.

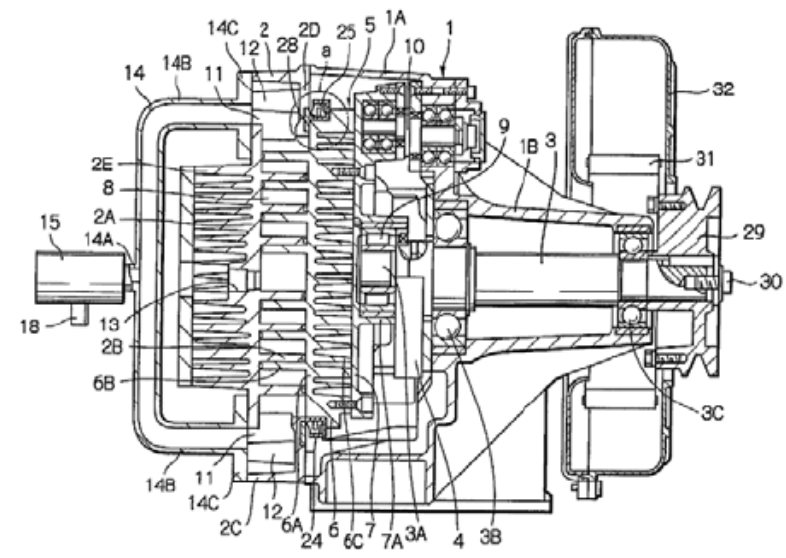

Fig. (22). Air OFSC.

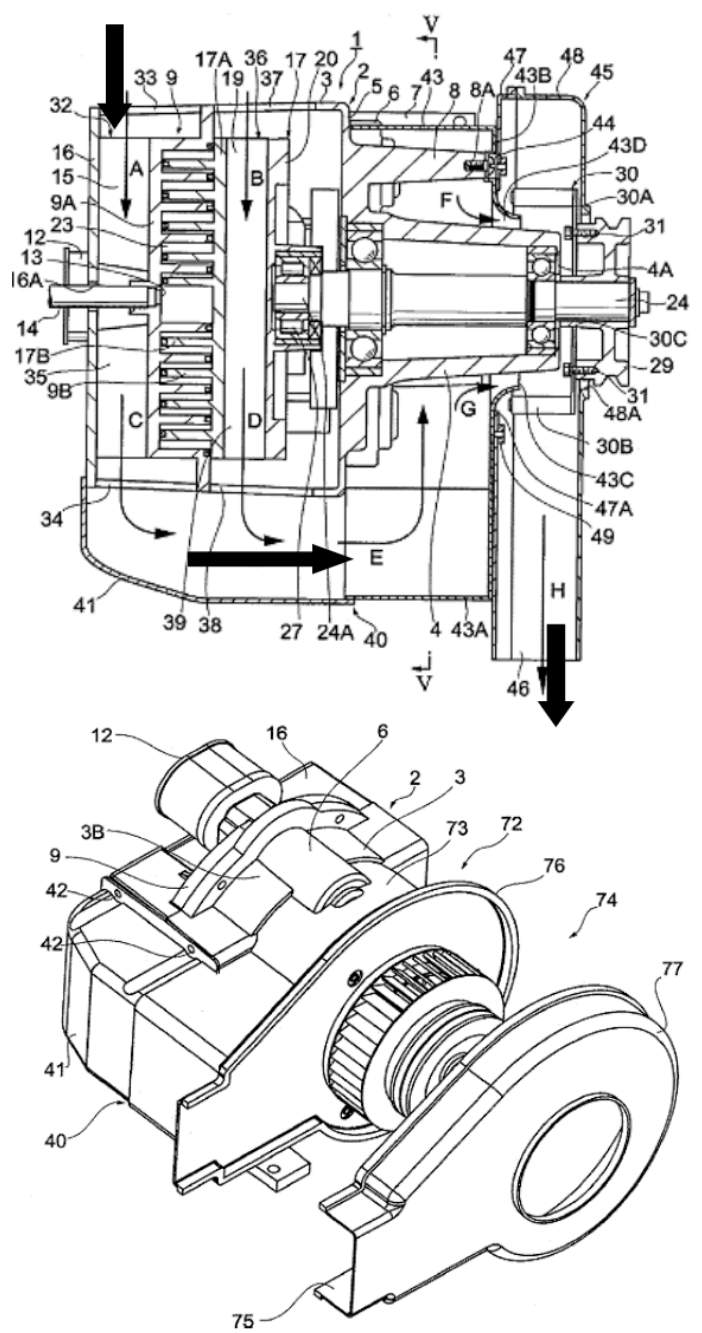

Fig. (23). Scroll fluid machine. 
Toshihiro [30] presented a two-stage (1 and 3,1 and 2) air-cooled OFSC as shown in Fig. (24). Water separator (13), cooling chamber (12) and fins (23 and 24) are used in OFSC to overcome the water hammer phenomenon, flowing back, and bad cooling of main parts.

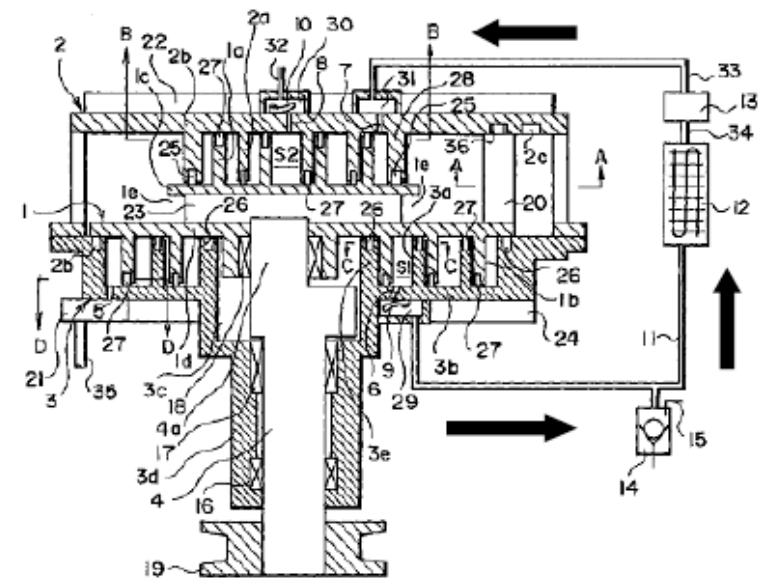

Fig. (24). Two stage scroll compressor.

Shuji [31] presented an oil-free two-stage vacuum pump including first and second pump stages as shown in Fig. (25) to obtain high compression ratio using small scroll size. The first and second pump stages have discharge spaces capable of communicating with each other via a bypass passage. The fan mounted on the shaft is used to cool the scrolls.

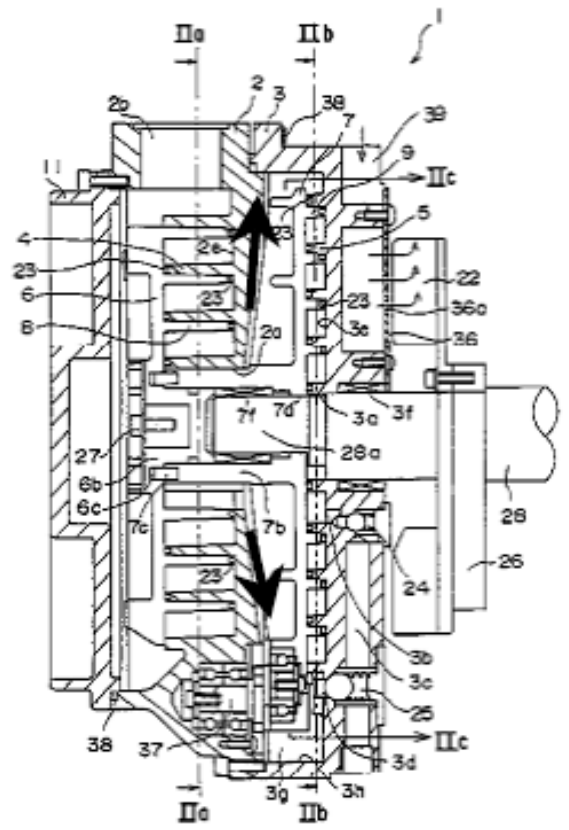

Fig. (25). Oil-free two stage scroll vacuum pump.

Christian [32] presented a totally OFSC with high suction volume flows and compression ratio, especially for rail vehicles as shown in Fig. (26). The fixed and orbiting scrolls (7 and 9) each respectively carry out a purely rational motion. No imbalance forces arise as long as the scrolls are respectively each properly balanced by themselves. The cooling system is also provided on the scrolls.

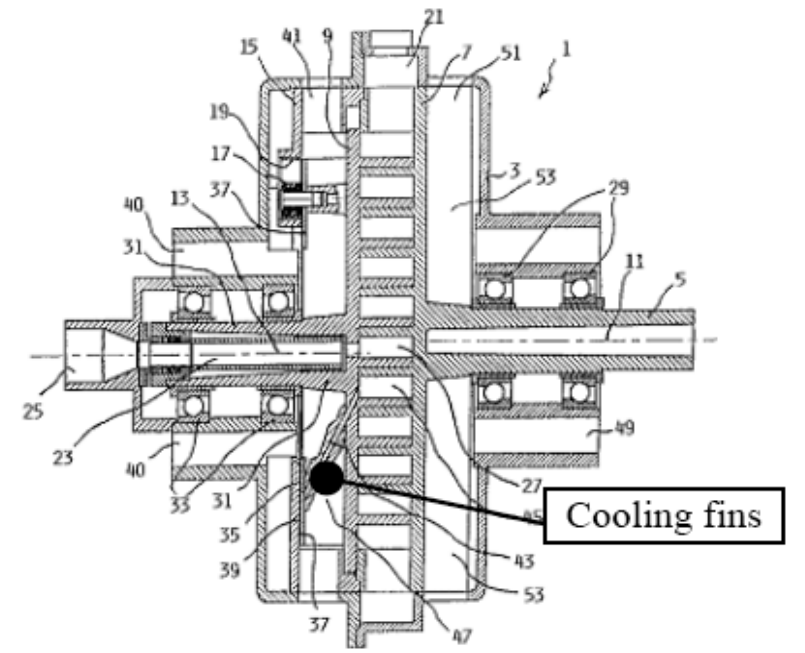

Fig. (26). OFSC used for rail vehicles.

Kazuaki [33] presented an OFSC as shown in Fig. (27). Grooves are formed on tips of the respective scroll laps, and elastic tip seals are fitted into the grooves in order to prevent leakage of compressed gas from between the laps and the end plates. Those surfaces of scrolls are subjected to an anodizing coating treatment while the orbiting scroll is subjected to NiPB treatment.
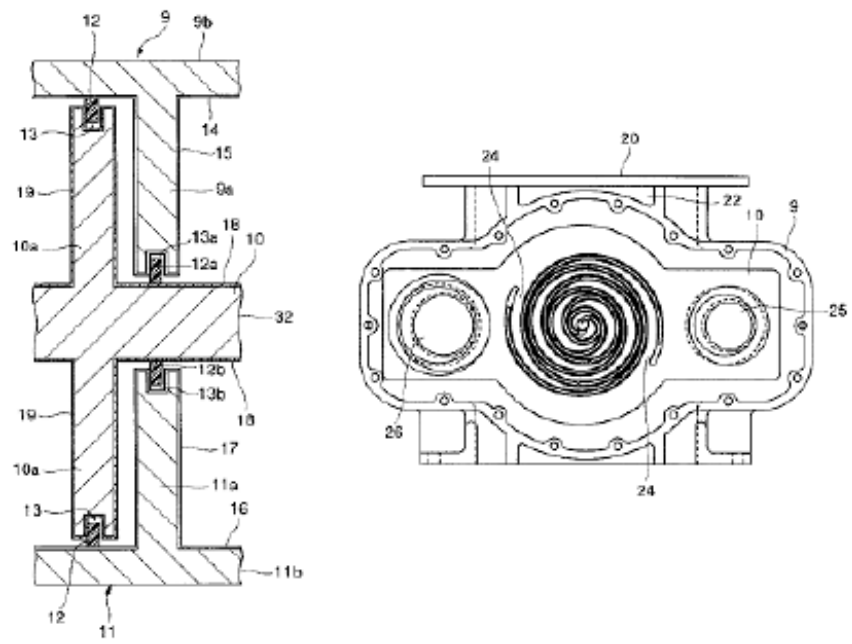

Fig. (27). The OFSC with elastic tip seal.

Hirokatsu, Hirotaka, Kazuaki \& Natsuki [34-37] presented a water injected scroll air compressor as shown in Fig. (28). The controller controls the injected-water flow rate according to temperature or pressure sensors. It can enhance compressor efficiency.

Kosuke [38] presented an OFSC as shown in Fig. (29). The cooling fan generates cooling wind and the cooling wind is send to the compressor body through the cooling wind passage.

Toshikazu [39] presented an OFSC as shown in Fig. (30). The variable thickness in the radial direction is applied according to different peripheral position. It can improve compression efficiency while prevent contact of scrolls. 

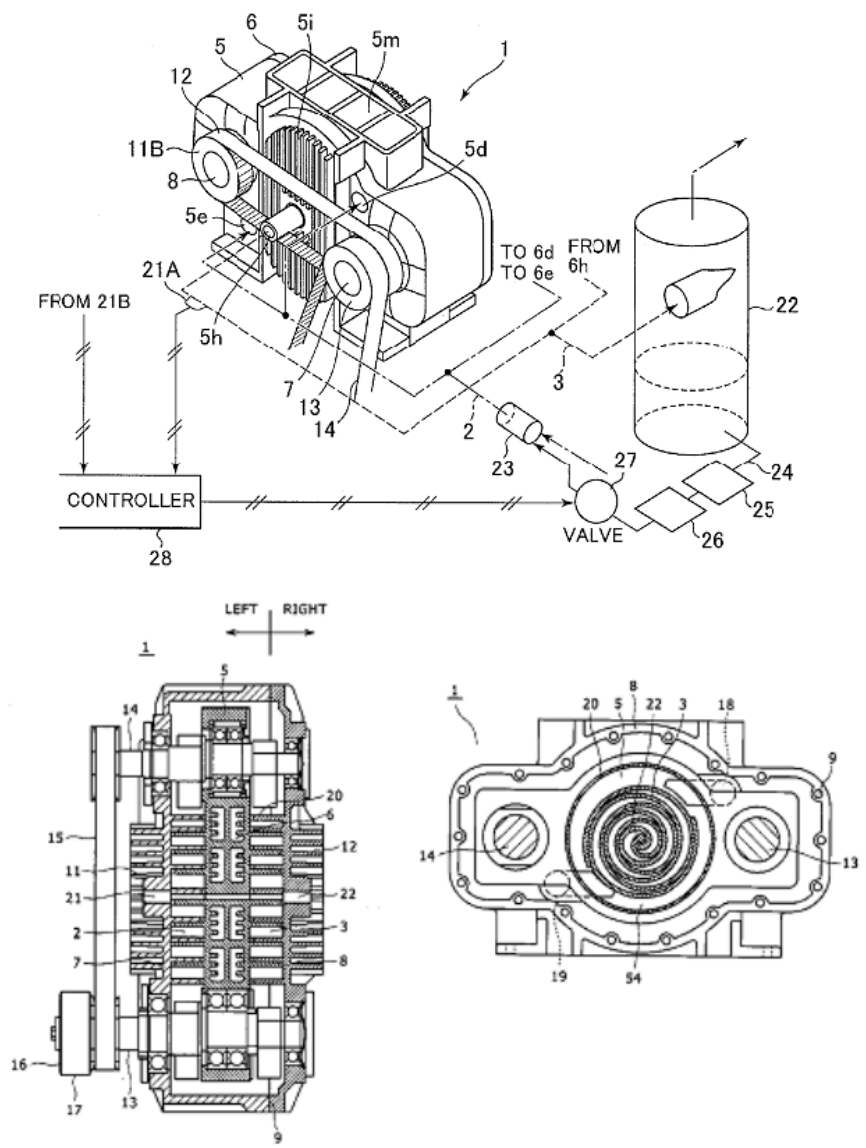

Fig. (28). A water injected scroll air compressor.

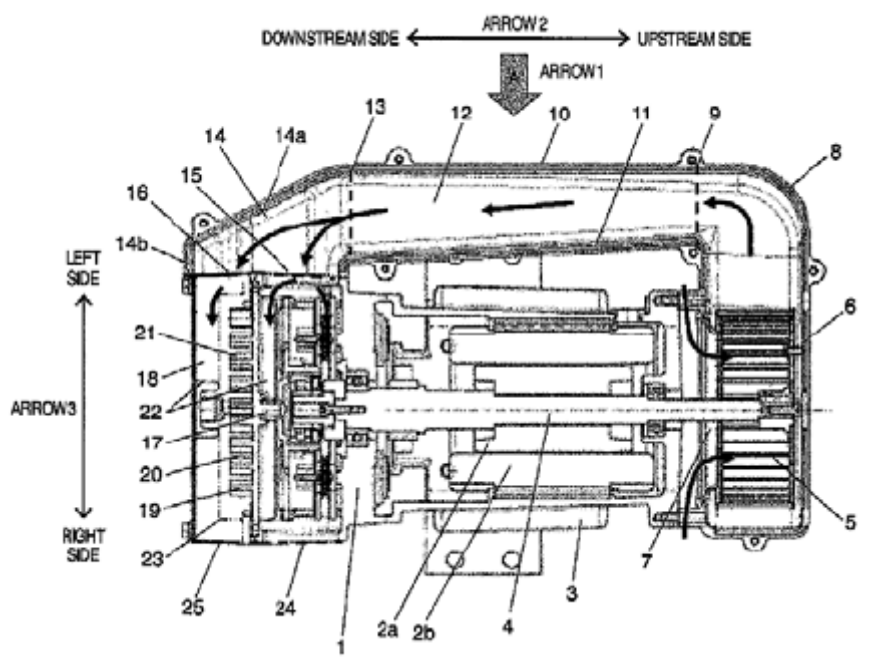

Fig. (29). The OFSC with cooling fan and wind passage.

Shimao [40] presented a central drive shaft-sliding knuckle combined with a peripheral crank pin-swing link mechanism (CSPS) to realize radial and axial compliant of orbiting scroll as shown in Fig. (31). The CSPS mechanism can be used for both dual floating scroll and single floating scroll structures to improve performances of scroll devices, particularly in oil-free operations.
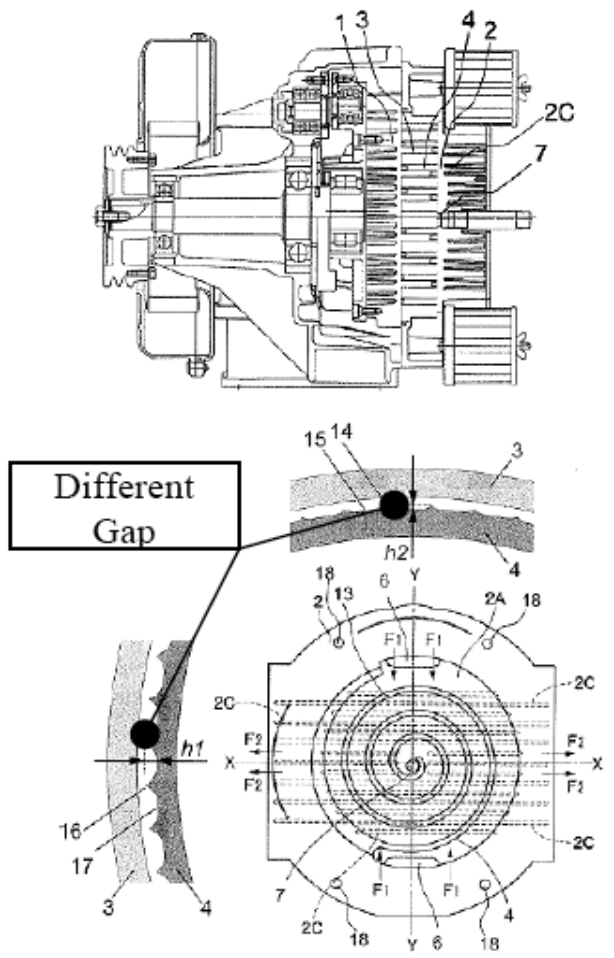

Fig. (30). The OFSC with different thickness.

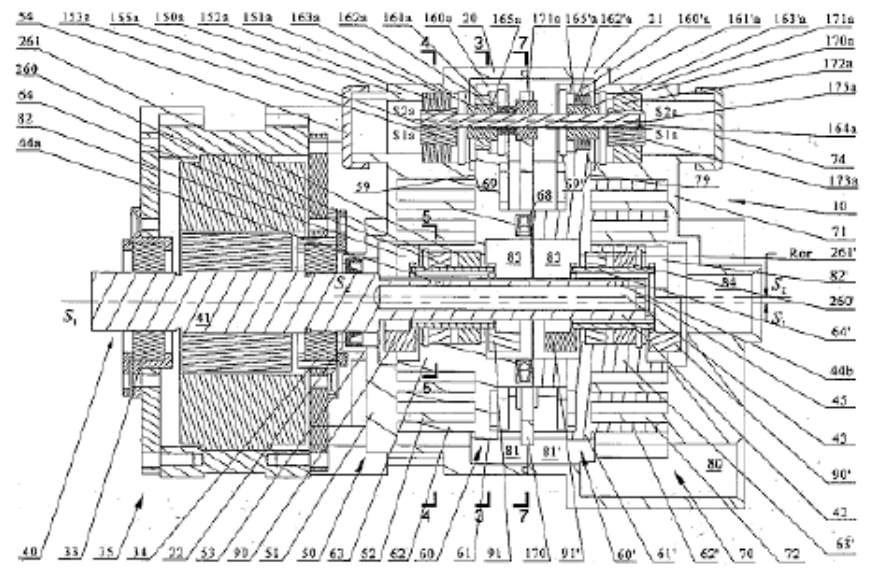

Fig. (31). Scroll fluid machine with floating scrolls.

Zhenmin [41] presented an OFSC used in air conditioning as shown in Fig. (32) which applied three cranks and return spring to reduce frictions and keep the optimal radical gap. The return spring is used to connect fixed scroll and frame. It can change with the pressure of working chambers.

At present, the requirements of processing accuracy assemble and measurements are very high for the OFSC. Many researchers have done a lot of works and presented many kinds of constructs. In industry for small displacement OFSC it can be cooled by the natural circulation of air. For large displacement OFSC it must adopt water or air forced cooling method to lower the compressor temperature. 


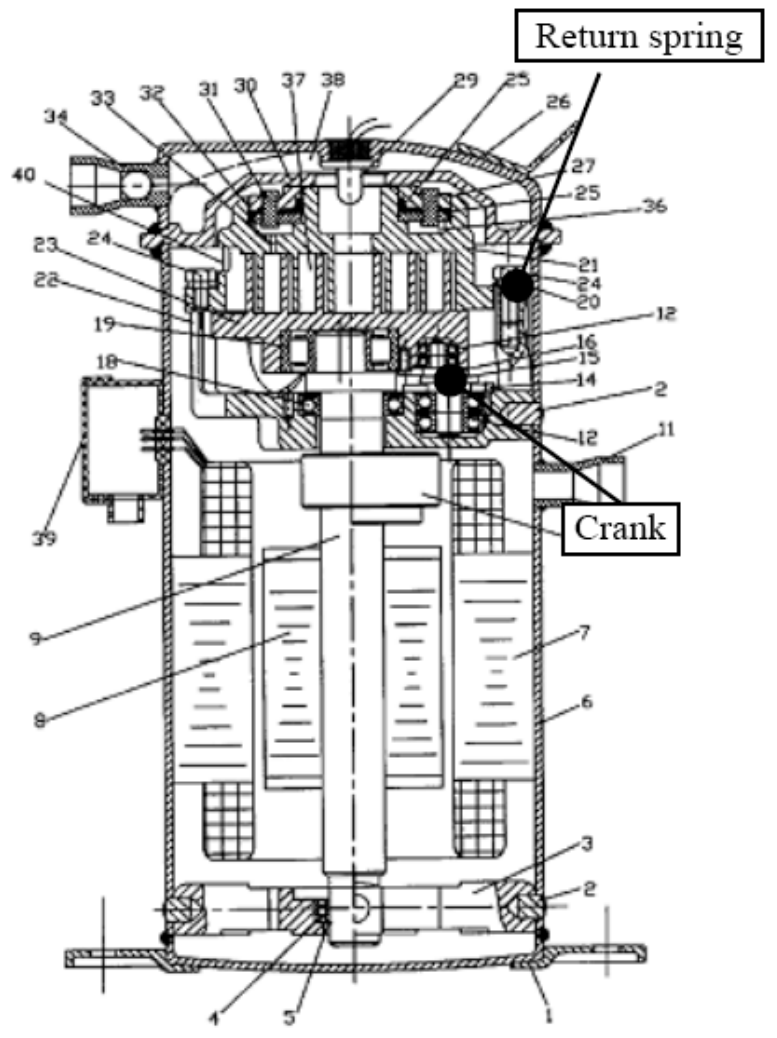

Fig. (32). The air conditioning OFSC.

\section{A TYPICAL OFSC}

Combining the former literatures and patents, a typical prototype of OFSC is shown in Fig. (33). Water cooling system will add additional device, it will make the system bigger. The injected water will destroy the rotor system balance. The fixed and orbiting scrolls will be damaged when the injected water in the working chambers is compressed. The injected water will also corrode the fixed and orbiting scrolls. So an air-cooling system is adopted. A cooling fan is used to cool the scroll compressor. When the shaft rotates, cooling air is sucked into air duct. Cooling air is allowed to flow out of a fixed outlet and an orbiting outlet through a fixed cooling passage provided at the OFSC. The heat of scrolls is taken away by the air circulation system. The reciprocating movement (Oldham ring) changes into rotation movement using crankshafts or ball bearing which can eliminate friction coefficients. Grooves are formed on tips of the scroll wraps as shown in Fig. (34). Different type of friction pairs can be selected. Tip seals using self-lubricating material (PTFE) or self-lubricating material and metal are fitted into the grooves in order to prevent leakage of compressed gas from between the wraps and the end plates. Those surfaces of scrolls are subjected to self-lubrication treatment. It can enhance sealing and reduce friction. Figure 34a is simple and the most widely-used structure in the industrial application. Figure 34c has the advantages of selfcompensation. Figure 34d can increase contact area to reduce friction. Figures $34 \mathbf{e} \& \mathbf{3 4 f}$ can offer superior surface lubricity of scroll top.
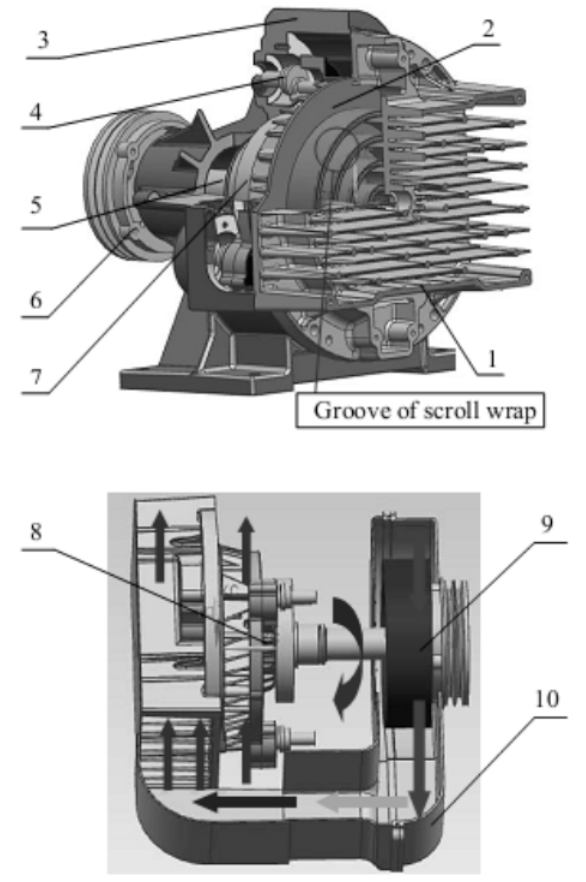

1. Fixed scroll 2. Orbiting scroll 3. Shell 4. Small crank 5. Crankshaft 6 . Belt with small counterbalance

7. Big counterbalance 8. Bracket 9. Cooling fan 10. Air duct

Fig. (33). The structure of OFSC.

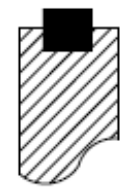

a

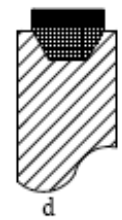

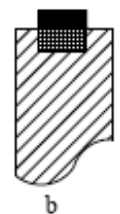

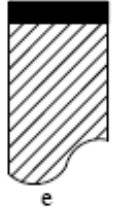

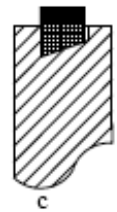

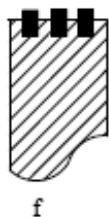

Self-lubrication material

PZ7 Scroll tooth

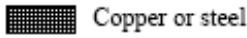

Fig. (34). The friction pairs of the scroll wraps.

\section{CURRENT \& FUTURE DEVELOPMENTS}

From the recent research on OFSC it has been shown that most researchers focus on two important factors, the first is sealing and the second is cooling. So many new structures and methods are put forward. In many patents the selflubrication materials and tip sealing are used to seal the moving parts and reduce friction. Water and air are used to cool the scrolls through cooling circulation system.

For future OFSC, the novel profile and structure with better geometry and dynamic performance will be adopted to reduce friction and improve the performances of scroll compressor. Long-life tip sealing material with optimal wear characteristics will be used to reduce friction coefficient for the scrolls and frame. Simple and optimized air cooling system will be used to cool scroll compressor. A highly reliable 
surface treatment of scrolls will be used to reduce manufacturing costs and improve the sealing performance. Antirotation small cranks or ball coupling will be used to decrease friction loss. All the new and advanced methods can also be used for OFSC machinery.

\section{CONFLICT OF INTERESTS}

The authors confirm that this article content has no conflicts of interest.

\section{ACKNOWLEDGEMENTS}

This work supported by National Natural Science Foundation of China (Grant No. 51275226); Natural Science Foundation of ZHEJIANG Province (Grant No.LY12E05010); Natural Science Foundation of GANSU Province (Grant No. 1212RJYA010) and Excellent Young Teachers Program of Chongqing, China.

\section{REFERENCES}

[1] Liu Z-Q. The scroll type fluid machinery and scroll compressor. China Machine Press: Beijing, 2009.

[2] Creux, L. Rotary engine. US801182 (1905).

[3] Chang Y-C. Family design of scroll compressors with optimization. PhD thesis, National Chiao Tung University, Tai Wan, 2007.

[4] http://www.freepatentsonline.com/ (Accessed on: October 25, 2015).

[5] Lai C-F, Huang A, Liang K-I. The development of oil-less scroll compressors used for fuel cells. The $4^{\text {th }}$ International Conference on Compressor and Refrigeration (ICCR). Xi'an Jiaotong University, Xi'an, P.R. China, October, 2003: 241-249.

[6] Zhao Y, Li L, Jiang S, Wei Z, Shu P. Research on OFSC with high speed in 30kW fuel cell. Appl Therm Eng 2003; 23(5): 593-603.

[7] Zhao Y, Li L, Wu H, Shu P. theoretical and experimental studies of water-injection scroll compressor in automotive fuel cell systems. Energ Convers Manage 2005; 46(9-10): 1379-92.

[8] Wang L, Zhao Y, Li L, Bu G, Shu P. Research on oil-free hermetic refrigeration scroll compressor. P I Mech Eng A-J Pow 2007; 221(7): 1049-56.

[9] Yanagisawa T, Fukuta M, Ogi Y. Performance of an oil-free scrolltype air compressor. Proc. of the ImechE Conf. Trans. on Compressors and their Systems. London, UK, 1999: 279-287.

[10] Yanagisawa T, Fukuta M, Ogi Y, Hikichi T. Performance of an oilfree scroll-type air expander. Proc. of the ImechE Conf. Trans. on Compressors and their Systems. London, UK, 2001: 167-174.

[11] Aoun B, Clodic DF. Theoretical and Experimental study of an oilfree scroll vapor expander. Proceedings of International Compressor Engineering Conference. Indiana, USA, 2008; 1188: 1-8.

[12] Lemort V, Quoilin S. Designing scroll expanders for use in heat recovery rankine cycles. Proc. of the ImechE Conf. Trans. on Compressors and their Systems. London, UK, 2009: 3-12.

[13] Shaffer BR, Groll EA. Performance of the use of plastics in oil-free scroll compressors. Proceedings of International Compressor Engineering Conference. Indiana, USA, 2012; 1267: 1-9.
[14] Shigeru, M., Masahiro, Y., Toshio, K. Oil-free scroll fluid machine with projecting orbiting bearing boss. US5098265 (1992).

[15] Seiichi, Y. Scroll type fluid machine having first and second bearings for the driving shaft. US5649817 (1997).

[16] Shuji, H., Masatomo, T., Takashi, S. Scroll-type fluid machinery with seals for the discharge port and wraps. US5258046 (1993).

[17] Shuji, H., Masatomo, T., Takashi, S. Scroll-type fluid machinery. EP0520487 (1995).

[18] Grenci, C.A., Clayton, D.R. Oil free scroll vacuum pump. US5366358 (1994).

[19] Akira, S., Kazuaki, S., Isamu, K., Shigeru, M. Scroll compressor with cooling holes in orbiting scroll. EP0520487 (1997).

[20] Zhenmin, H. Constant low temperature oil-free air scroll compressor. CN101324235 (2008).

[21] Akira, S., Masakazu, A. Oil-free scroll compressor. US5358387 (1994).

[22] Masaru, T., Shuji, H. Oil-free scroll vacuum pump. EP0798463 (1997).

[23] Shuji, H., Masaru, T. Oil-free scrolled vacuum pump. EP0754860 (1997).

[24] Shuji, H., Masaru, T. Oil-free scroll vacuum pump having a gas ballast part. US5743719 (1998).

[25] Guangyu, W., Zhenhou, Z., Xiangling, K., Zaihang, L. Low-speed oil-free scroll vacuum pump. CN201250774 (2009).

[26] Guangyan, Y. Oil-free scroll fluid machine. CN202520549 (2012).

[27] Kazuaki, S., Isamu, K., Natsuki, K., Akira, S. Partition means for directing air flow over a cooler in an oilless scroll compressor. US6210132 (2001).

[28] Kazutaka, S., Hideaki, I., Junichi, I. Scroll compressor. US20020102174 (2002).

[29] Atsushi, K, Toshitsugu, S., Kazutaka, S., Yoshiyuki, K. Scroll fluid machine. US20100221134 (2010), US8858203 (2014) \& US20140294641 (2014)

[30] Toshihiro, H. Two stage scroll compressor. EP0863313 (1998).

[31] Shuji, H., Masaru, T. Oil-free two stage scroll vacuum pump and method for controlling the same pump. US5961297 (1999).

[32] Christian, H., Wilfried, Z., Robert, F. Spiral compressor, useful in particular to generate compressed air for rail vehicles. US6062833 (2000).

[33] Kazuaki, S., Isamu, K., Natsuki, K., Akira, S., Tatsuo, N., Muneo, M., Shigeru, M. Scroll compressor and method of manufacturing same. US6142755 (2000).

[34] Hirokatsu, K., Hirotaka, K., Kazuaki, S., Toshiaki, Y. Oil-free scroll compressor. US20100158733 (2010) \& US8202057 (2012).

[35] Hirotaka, K., Kazuaki, S., Natsuki, K., Hirokatsu, K. Waterinjection type scroll air compressor. US20110129362 (2011) \& US8585376 (2013).

[36] Kazuaki, S., Natsuki, K., Hirotaka, K. Water injected scroll air compressor. US8721308 (2014).

[37] Natsuki, K., Kazuaki, S., Hirotaka, K., Masakazu, A. Water injected scroll air compressor. US9145892 (2015).

[38] Kosuke, S., Kiminori, I., Yoshio, K. Scroll fluid machine with cooling fan and passage. US9115719 (2015).

[39] Toshikazu, H. Scroll type fluid machine. EP2881586 (2015) \& US20150152863 (2015).

[40] Shimao, N. Scroll-type fluid displacement apparatus with fully compliant floating scrolls. US20070172373 (2007).

[41] Zhenmin, H. Oil-free air condition scroll compressor. CN1828189 (2006). 